\title{
USE OF HEATED HELIUM TO SIMULATE SURFACE PRESSURE FLUCTUATIONS ON THE LAUNCH ABORT VEHICLE DURING ABORT MOTOR FIRING
}

\author{
J. Panda ${ }^{\dagger *}$, G. H. James ${ }^{\ddagger}$, N. J. Burnside ${ }^{\dagger}$, R. K. Fong ${ }^{\dagger}$, V. A. Fogt ${ }^{\ddagger}$, J. C. Ross ${ }^{\dagger}$ \\ ${ }^{\dagger}$ NASA Ames Research Center, Moffett Field, CA \\ ${ }^{\ddagger}$ NASA Johnson Space Center, Houston, TX
}

\begin{abstract}
The solid-rocket plumes from the Abort motor of the Multi-Purpose Crew Vehicle (MPCV, also know as Orion) were simulated using hot, high pressure, Helium gas to determine the surface pressure fluctuations on the vehicle in the event of an abort. About 80 different abort situations over a wide Mach number range, $(0.3 \leq M \leq 1.2)$ and vehicle attitudes $\left( \pm 15^{\circ}\right)$ were simulated inside the NASA Ames Unitary Plan, 11-Foot Transonic Wind Tunnel. For each abort case, typically two different Helium plume and wind tunnel conditions were used to bracket different flow matching critera. This unique, yet cost-effective test used a custom-built hot Helium delivery system, and a $6 \%$ scale model of a part of the MPCV, known as the Launch Abort Vehicle. The test confirmed the very high level of pressure fluctuations on the surface of the vehicle expected during an abort. In general, the fluctuations were found to be dominated by the very nearfield hydrodynamic fluctuations present in the plume shear-layer. The plumes were found to grow in size for aborts occuring at higher flight Mach number and altitude conditions. This led to an increase in the extent of impingement on the vehicle surfaces; however, unlike some initial expectations, the general trend was a decrease in the level of pressure fluctuations with increasing impingement. In general, the highest levels of fluctuations were found when the outer edges of the plume shear layers grazed the vehicle surface. At nonzero vehicle attitudes the surface pressure distributions were found to become very asymmetric. The data from these wind-tunnel simulations were compared against data collected from the recent Pad Abort 1 flight test. Inspite of various differences between the transient flight situation and the steady-state wind tunnel simulations, the hot-Helium data were found to replicate the PA1 data fairly reasonably. The data gathered from this one-of-a-kind wind-tunnel test fills a gap in the manned-space programs, and will be used to establish the acoustic environment for vibro-acoustic qualification testing of the MPCV.
\end{abstract}

List of Symbols:

U, u: velocity

$\rho:$ density

M: Mach number

$\mathrm{J}:=$ momentum flux in plume/ that in free-atream

c: speed of sound

St: Strouhal frequency $=\mathrm{fD} / \mathrm{U}$

$\mathrm{m}$ : molecular weight

p: pressure

$\gamma$ : ratio of specific heats

$\mathrm{R}$ : universal gas constant

$\tau$ : time

D: Nozzle diameter

$\mathrm{q}$ : Dynamic pressure $=1 / 2 \mathrm{\rho u}^{2}=1 / 2 \gamma \mathrm{pM}^{2}$

Re: Reynolds number

$\mathrm{Cp}_{\mathrm{rms}}=$ Normalized rms pressure fluctuations

t: Temperature

I: turbulence intensity

\author{
psd: Power Spectral Density \\ $\theta$ : azimuthal angle \\ $\alpha$ : Angle of attack \\ $\beta$ : Sideslip angle \\ $\mathrm{f}$ : frequency \\ $\mathrm{W}_{\mathrm{e}}$ : Mechanical power per unit nozzle area \\ Subscripts: \\ $\mathrm{f}$ : full-scale flight condition \\ t: wind tunnel free-stream condition \\ $\mathrm{j}$ : fully-expanded plume condition \\ a: ambient/free-stream condition \\ e: nozzle exit condition \\ h: Helium plume conditions \\ r: rocket-motor plume conditions \\ 0 : plenum/total condition \\ $\mathrm{i}, \mathrm{k}$ : indices for repititive sum over 1, 2, 3
}

\section{INTRODUCTION}

The Launch Abort Vehicle (LAV) is intended to separate the Crew Module from the rest of the rocket vehicle in case of an emergency. This is achieved via firing a high-thrust, solid-rocket motor, called the Abort Motor (AM),

\footnotetext{
* Associate Fellow, AIAA
} 
attached to the apex of the LAV (Fig. 1). The high-velocity and high-temperature plumes from the solid rocket flows out of four nozzles that are canted approximately $20^{\circ}$ to the vehicle axis, and flows above the Boost Protective Cover (BPC) which surrounds the front part of the Crew Module. The radiated and hydrodynamic fluctuations in the high-speed rocket plumes is expected to create intense surface pressure fluctuations everywhere on the vehicle surface. The acoustics environment from the abort motor is unique to this configuration of a mannedspace-vehicle, and far exceeds all acoustic levels encountered during liftoff, ascent through the atmosphere (transonic and maximum dynamic-pressure) and during reentry phases of a nominal flight. An important part of a spacecraft design is the vibro-acoustic certification of all components via rigorous testing in reverberant chambers and on shaker tables. The surface pressure fluctuations on the vehicle are the primary contributor to the acoustic and vibrational levels used for these qualification tests. It is expected that the limiting environment for most of the structural components, propulsive systems, electronic and navigational sub-systems and life support system of the Multi-Purpose Crew Vehicle (MPCV) and the LAV will arise from the firing of the Abort Motor.

Unfortunately, we were unable to find much guidance on abort-acoustics from the past manned space programs: Apollo, Mercury and Gemini. The Space Shuttle did not use a rocket-firing-based Abort scenario. There are reports of the use of unsteady pressure transducers in one of the abort test flights from the Apollo era, however, actual data were unavailable. As a first step towards an understanding of the plume flowfield, results from the Computational Fluid Dynamic (CFD) simulations were used in the current program (Fig 1). Although CFD can provide estimates of the time-averaged flow properties, the current abilities fall short of estimating the unsteady pressure fluctuations. The lack of a database, and low confidence in the prediction schemes made it impossible to determine the acoustics fluctuations for the design of a safe vehicle. This led to a test-based campaign to establish the vibro-acoustics environemnt for the MPCV and the LAV. The present hot-Helium test, named 80-AS, is a part of that campaign. The other parts of this campaign occured (a) during the static-fire test of the Abort Motor, ST1; (b) during the flight test of the unmanned Pad Abort 1; (c) another wind tunnel test, 51AS, where mildly heated compressed air was used to simulate the abort plumes. The use of solid rocket motors in transonic wind tunnels was studied as an alternate to the present test; however, the effort was found to be cost-prohibitive.

This report focuses on the hot-Helium test. The primary goal is to summarize various considerations for the selection of Helium to simulate the rocket plumes, to present the relationships needed to scale the model scale Helium plume data to the full scale flight vehicle, and to present some sample results from this rest. Additionally, model-scale wind tunnel data are compared against a full-scale flight data collected from the Pad Abort I vehicle.

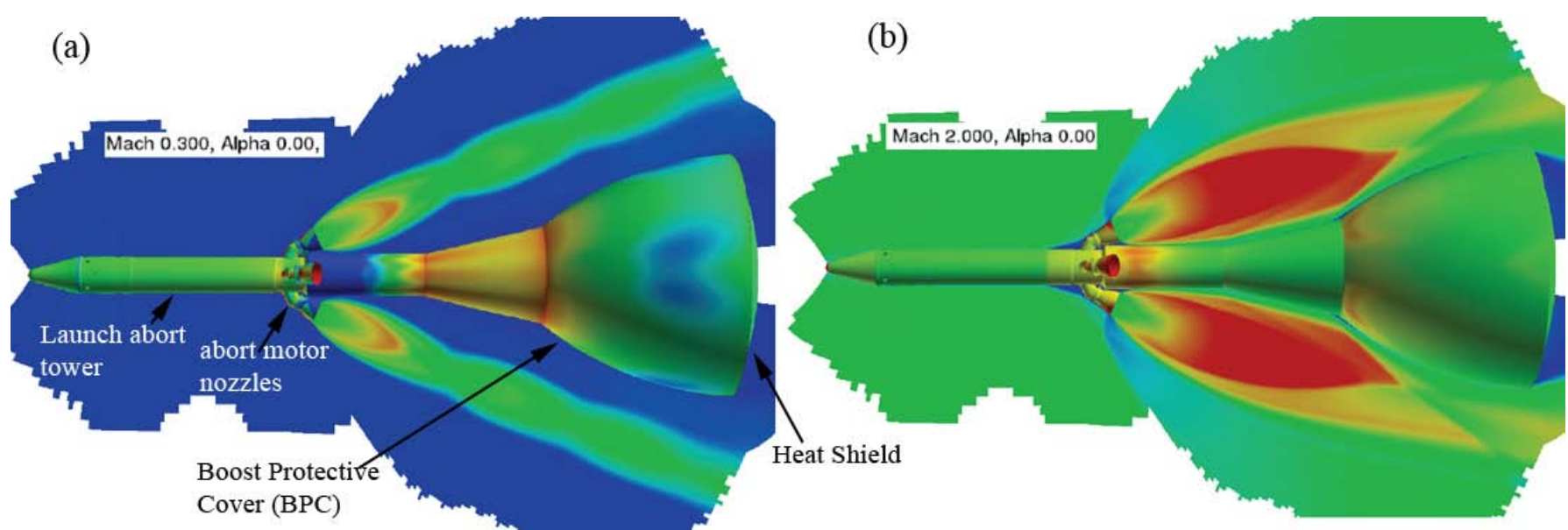

Fig 1. Inviscid CFD solution of the Abort Motor plume over the Launch Abort Vehicle during aborts initiated at flight Mach number (a) $\mathrm{M}_{\mathrm{f}}=0.3$ and (b) $\mathrm{M}_{\mathrm{f}}=2.0$. (Source: James S. Greathouse, NASA JSC).

\section{IA. The case for Helium}

Reorganization of the exact equations of motion, Navier-Stokes and Continuity, shows that the pressure fluctuations $\mathrm{p}(\mathbf{X}, \tau)$ at a point $\mathbf{X}$ on a rigid body is given by a volume integral of the turbulent fluctuations in its neighborhood. The turbulent fluctuations are expressed through the Lighthill's turbulence stress tensor $\mathbf{T}_{\mathbf{i k}}$ (Ffowcs Williams,1965):

$$
p(\boldsymbol{X}, \tau)=\frac{1}{2 \pi} \int_{V} \frac{\partial^{2} \boldsymbol{T}_{\boldsymbol{i} \boldsymbol{k}}}{\partial Z_{i} \partial Z_{k}}\left(\boldsymbol{Z}, \tau-\frac{r}{c}\right) \frac{d \boldsymbol{Z}}{r}
$$


Here $\mathbf{Z}$ is a position vector within the volume, and $r$ is the distance separating the point source $\mathbf{Z}$ from the position on the surface $\mathbf{X}, r=|\mathbf{Z}-\mathbf{X}|$. Neglecting the viscous contributions, which are deemed secondary, the Lighthill stress tensor is expressed as following:

$$
\boldsymbol{T}_{\boldsymbol{i k}}=\rho u_{i} u_{k}+\delta_{i k}\left(p-c^{2} \rho\right)
$$

Here $\mathrm{u}_{\mathrm{i}}$ and $\mathrm{u}_{\mathrm{k}}$ are velocity componenets along $\mathrm{i}$ - and $\mathrm{k}$ - directions, and $\delta$ is the Kronecker delta. Although the above equation can not be used directly, it provides the necessary guidance for setting up an acoustic test using a substitute gas. It shows that there are two primary variables: (a) fluctuations in puu (related to the local dynamic pressure), and (b) entropy fluctuations associated with changes in $\left(p-c^{2} \rho\right)$. In a low speed isentropic flow the second term is insignificant, while in a solid rocket plume, it may be of importance.

At a first glance Helium and the rocket plume appear to be vastly different. The chemical composition of Helium (inert gas) is certainly different from that of a solid rocket plume $\left(\mathrm{Al}_{2} \mathrm{O}_{3}\right.$ powder, steam, $\mathrm{H}_{2}, \mathrm{HCl}, \mathrm{CO}, \mathrm{CO}_{2}$ etc). There are also significant differences in the molecular weight, specific heat, thermal conductivity etc.

However, equations 1 and 2 shows that these parameters do not directly influence the noise generation properties of jet plumes. For noise generation the important parameters are velocity, sound speed, density, and plume size.

Among the different choices of the substitute gas, heated Helium is found to provide the closest match to a rocket plume for the above acoustically relevant parameters. There are other derived parameters, such as Mach number, and static pressure ratio at the nozzle exit, used in various noise modeling. If this list needs to be shortened to one central parameter then it is the very high speed of sound at low tepmerature that makes Helium the most suitable substitute gas. The sound speed in a gas at temperature $t$ is given by:

$$
c=\sqrt{\frac{\gamma R t}{m}},
$$

Table I (a) shows the relative sound speeds in various gases of interest. The sound speed in the ambient temperature Helium is nearly three times that of air, and is close to that of a solid rocket plume. The only other gas that has a faster sound speed is Hydrogen which precedes Helium in the Periodic table. Hydrogen is extremely combustible; and unsuitable for use in the confinements of a wind tunnel.

Table I. Relative sound speed

\begin{tabular}{|l|l|l|l|}
\hline & $\gamma$ & m: molecular $w t$ & $\mathrm{c}(\mathrm{ft} / \mathrm{s})$ \\
\hline Air at room temp t $=$ 540R & 1.4 & 29 & 1139 \\
\hline Helium at room temp t = 540R & 1.66 & 4 & 3339 \\
\hline Solid rocket plume at 5700R & 1.214 & 26.5 & 3604 \\
\hline
\end{tabular}

Although Table I(a) shows that the ambient temperature He has a similar sound speed as that of a rocket plume, there is an additional factor that arises when a compressed gas is expanded through a nozzle; the increase in Mach number accompanies a drop in temperature. To compensate for this drop additional heating of Helium is required. Heating of pure Helium brings the velocity of the resulting jet close to that of a rocket plume. Finally, gas density: $\rho=\mathrm{pm} / \mathrm{Rt}$ is a function of the molecular weight which is far lower for Helium than rocket-plume. Therefore Helium is able to replicate the low density of a solid rocket plume at a lower supply pressure and temperature. Note that the fluctuations of temperature do not enter directly in the equation 1 , neither is the ratio of specific heat, $\gamma$. Therefore, gases with dissimilar $\gamma$ heated to different temperature can produce the same fluctuations in pressure. These are the primary reasons for the use of Helium.

The primary differences between Helium and the plume of a solid rocket motor arise due to three factors: (a) a lack of after-burning, (b) a lack of particle-damping and, (c) a mismatch in the ratio of specific heat. The presence of the unburned fuel and combustible chemicals produces afterburning in the rocket plume which cannot be reproduced in Helium. Equation 2 above shows that the entropy fluctuation is a source of pressure fluctuation; the combustion process in the shear layer of a rocket plume is expected to produce some entropy fluctuations; although, no estimate of its impact is available from the existing literature.

The influence of the solid $\mathrm{Al}_{2} \mathrm{O}_{3}$ powder in the solid rocket plume can also not be replicated in the Helium simulation. It is known that the presence of solid particles can reduce the sound speed, cause attenuation of sound waves and can help break down the shock system (Marble 1970, Pelanti \& Leveque 2006). This could lead to a lowering of the radiated noise. Additionally, the mismatch in the ratio of specific heats makes matching both density and sound speeds between a Helium and a rocket plume difficult. Also the diameter of an under-expanded Helium plume is smaller than that of a comparable rocket. All of these bring about a set of flow parameters some of 
which can be matched between a helium and Rocket plume and some cannot. The effect of various choices made in the past experiments, is discussed next.

\section{IB. Past experience of using Helium to simulate plume noise:}

In the past Helium plumes were used mostly to study the far-field acoustic fluctuations. Almost all of these applications involve simulating noise from the static jets, without the influence of any forward flight. The present LAV application, on the other hand, involves the static firing, and a large range of forward flight conditions. To simulate the relatively low temperature and low velocity air plumes produced by commercial and military jet engines, unheated Helium is mixed with unheated air (Kinzie \& McLauglin, 1999; Doty \& McLaughlin 2002; Papamoschou, 2007) to reduce the sound speed, and to make the mixture velocity comparable to that of the jet engines (typical $\mathrm{u} / \mathrm{c}_{\mathrm{a}} \sim 1.8$ and $\mathrm{T}_{0} \sim 1400^{\circ} \mathrm{F}$ ). Even for these lower temperature simulations not all parameters can be matched. These simulations tried to match either the sound speed or the air density of jet engine plumes. Matching the sound speed was found to provide the best result. The overall agreement between the hot air and Helium-air mixture was found to be within 1.2dB.

Recently, Greska et al $(2008,2009)$ compared the near acoustics field of a heated Helium plume with that created by heated air. They have proposed the use of the Oertel convective Mach number $\mathbf{M}_{\text {co }}$ to determine the acoustic similarity: $\mathrm{M}_{\mathrm{co}}=\left(\mathrm{u}_{\mathrm{j}}+1 / 2 \mathrm{C}_{\mathrm{j}}\right) /\left(\mathrm{c}_{\mathrm{j}}+\mathrm{c}_{\mathrm{a}}\right)$. By definition $\mathrm{M}_{\mathrm{co}}$ includes all relevant velocity parameters involved in sound generation and far-field radiation. They found a fair match in overall levels between the two plumes. One noticeable difference was that the peak acoustic source in a Helium jet appeared closer to the nozzle exit. The difference was attributed to a shortened length of the potential core in the Helium jet.

Simulation of the solid rocket plume by heated, pure Helium, by Morgan \& Young (1963) is the most relevant to the present effort. The authors compared near \& far field radiations from a solid rocket plume with those from Helium plumes created via different plenum pressure and temperature conditions. The chamber pressure and temperature of the solid rocket plume were respectively, 635psia and 6000R; while those for the Helium plume were varied between 44psi to 344psi, and 750R to 1560R. It is to be noted that the solid rocket plumes are typically under-expanded, however unlike cold air jets, the broad-band shock noise peaks are not discernable. The mixing noise dominates the spectra at all polar angles. Morgan \& Young observed that the best matching in the near and far field acoustic levels were obtained when the velocity, Mach number and pressure at the nozzle exit were matched between the Helium and the rocket plumes. In spite of the mismatch in the density, the jet mechanical power per unit nozzle area, and some other parameters, the overall sound pressure levels were found to be within $2 \mathrm{~dB}$ for most of the microphone positions. The data showed a small difference between the rocket and the Helium plumes close to the nozzle exit and a larger difference further downstream (20 nozzle diameters) from the plume. The point to take away is that a different set of matching conditions can lead to higher or lower levels at different frequency bands.

\section{IC. Expected influence of LAV forward flight}

Since the rocket-motor assisted abort can occur anywhere between Mach zero (pad abort) through a high supersonic Mach number, the surface pressure fluctuations are expected to vary significantly. There are two new physical phenomena that come into play with forward flight: (a) a progressive increase in the plume diameter with altitude, and (b) the distortions of the plume due to interactions with the free-stream. The degree of underexpansion, expressed by the ratio of the nozzle exit pressure and the ambient pressure $\left(\mathrm{p}_{\mathrm{e}} / \mathrm{p}_{\mathrm{a}}\right)$ increases with the vehicle altitude, primarily due to the lowering of the latter. As the pressure inside the plume relaxes, the diameter grows larger than the nozzle exit diameter. Since the centerlines of the plumes lie very close to the BPC, the increase in the diameter is expected to lead to a progressively increasing scrubbing of the motor surface and the BPC. The CFD simulation of Figure 1 clearly shows this trend. A measure of the plume growth is its 'fully expanded diameter' $\mathrm{D}_{\mathrm{j}}$ which can be estimated from a formula proposed by Tam \& Tanna (1982):

$$
\frac{D_{j}}{D_{e}}=\left(\frac{M_{e}}{M_{j}}\right)^{0.5}\left[\frac{1+\frac{1}{2}(\gamma-1) M_{j}^{2}}{1+\frac{1}{2}(\gamma-1) M_{e}^{2}}\right]^{\frac{\gamma+1}{4(\gamma-1)}}
$$

Table II shows a comparison of the plume diameter at different abort altitudes. At 60,000 ft altitude the plume diameter is so large that the entire front side of the BPC encounters direct impingement. Therefore it can be said 
that for the high altitude abort scenarios, fluctuations due to the direct scrubbing and impingement of the plume will play a critical role in the unsteady pressure environment.

Table II. LAM plume diameter at different altitudes

\begin{tabular}{|l|l|l|l|}
\hline Altitude (ft) & 0 & 20,000 & 60,000 \\
\hline Atmospheric pressure (psf) & 2100 & 970 & 150 \\
\hline Fully-expanded plume dia/nozzle exit dia & 1.27 & 1.76 & 3.6 \\
\hline
\end{tabular}
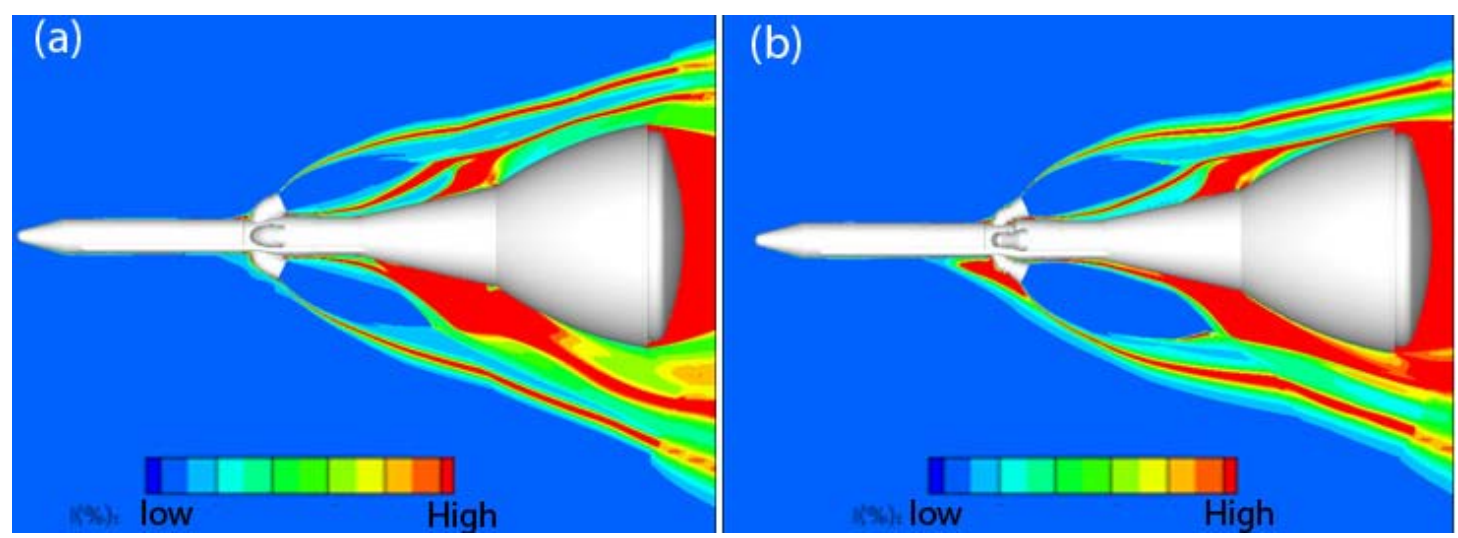

Fig 2. Distribution of the turbulence intensity fluctuations on LAV in (a) hot-Helium simulation, \& (b) full-scale vehicle during an abort flight at $\mathrm{M}_{\mathrm{a}}=1.6, \alpha=-10^{\circ}, \beta=-10^{\circ}$ (William J. Coirier, Kratos/DFI, 2009).

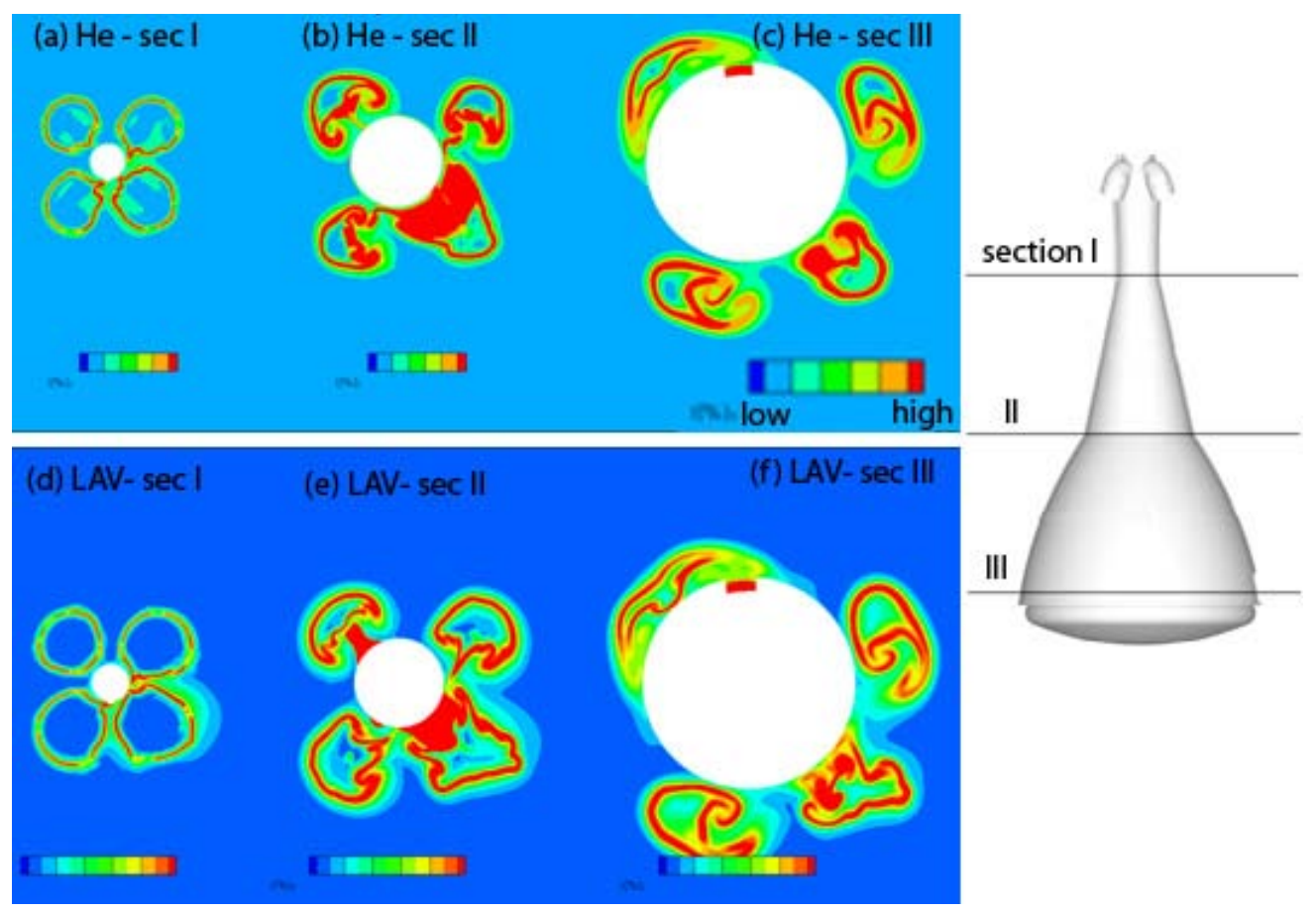

Fig 3. Cross-sectional views of the plume structures (plotted variable is the intensity of turbulence fluctuations) from three indicated axial stations; (a), (b), (c) hot-Helium simulation; (d), (e), (f) full-scale LAV. The $\mathrm{M}_{\mathrm{a}}, \alpha$ and $\beta$ are the same as in the figure above (William J. Coirier, Kratos/DFI, 2009).

The second phenomenon, the interactions between the free-stream and the plume is far more complex. At transonic/supersonic flight regimes there appears a complex shock wave pattern on the LAV surface. The flight stream is also expected to deflect the plumes closer to the LAV surface, and a situation similar to "jets-in-crossflow" appears. The situation becomes more complex at non-zero angle of attack. In order to gain some understanding of the underlying flow features, a computational effort was put in place. William Coirier (2009) used a RANS code with Menter's SST model and Sarkar compressibility correction. Both the flight stream and the 
plumes were assumed to be calorically perfect gas with constant molecular weight and specific heats. The goal of the computational effort was to provide a comparison between the solid-motor plume and that of the Helium plume over the full-scale and model-scale LAV, respectively. A large set of solutions were obtained covering a range of Mach number, $\alpha$ (angle of attack) and $\beta$ (sideslip angle). Figures 2 and 3 show distributions of turbulent intensity fluctuations ( $I=\frac{100}{U} \sqrt{\frac{2}{3} K} \quad U$ : free - stream velocity, $K$ : turbulent kinetic energy) obtained from one such solution. Figure 2 shows the diameter modulation of the under-expanded plume associated with the internal shock patterns. Figure 3, on the other hand, shows that appearance of "kidney vortices" and their mutual interactions, which makes the three plumes cluster at the leeward side, while the remaining plume is spread over a large part of the windward side. The primary point is that the wind-tunnel simulation of Helium plume, in spite of its higher $\gamma$, makes a close duplication of the flow-field during an abort. Another observation is that the momentum ratio (J= momentum in the plume/that in the free-stream), a parameter charactering the "jet-in-cross-flow" situations needs to be monitored in selecting the wind-tunnel conditions.

To simulate the above forward flight effects, the test had to be conducted in a transonic wind tunnel. The wind tunnel conditions were not an exact match to the wide range of flight conditions expected to be encountered in the abort situations. Therefore, a scaling based on the ratio of the dynamic pressure in the flight stream $\mathrm{q}_{\mathrm{f}}$ and that in the wind tunnel stream $\mathrm{q}_{\mathrm{t}}$ needs to be applied to the pressure fluctuation levels measured in the wind tunnel:

$$
\frac{p_{f}^{\prime}}{p_{t}^{\prime}}=\left(\frac{q_{f}}{q_{t}},\right. \text { other variables) (nominal ascent) }
$$

The above scaling is valid in the absence of a plume, such as data collected to simulate nominal flights. The presence of the plume brings a second ratio of dynamic pressures: that in the rocket plume $\mathrm{q}_{\mathrm{r}}$ to that in the Helium plume $\mathrm{q}_{\mathrm{h}}$, which also needs to be accounted for.

$$
\frac{p_{f}^{\prime}}{p_{t}^{\prime}}=f\left(\frac{q_{f}}{q_{t}}, \frac{q_{r}}{q_{h}},\right. \text { other variables) (powered abort) }
$$

In other words, the scaling problem, synonymously the matching problem, switches to a two q-ratio match.

\section{ID. Setting-up the test matrix and matching of the plume properties:}

Besides the two q-ratios, a host of other parameters needs to be matched for an ideal representation of the forward flight effect. Note that the properties of under-expanded jets are expressed by two sets of parameters: those at the nozzle exit (such as $M_{e}, U_{e}, \rho_{e}$, pressure ratio: $p_{e} / p_{a}$ etc.) and those at the fully expanded condition $\left(M_{j}, U_{j}, \rho_{j}\right.$, $\mathrm{D}_{\mathrm{j}}$ etc.). A fully-expanded condition is achieved when the pressure inside an under/over expanded plume relaxes to the ambient condition. The CFD simulations presented above show that the plume goes through a series of expansion-shock processes over the vehicle. The literature on under-expanded jets characterizes these changes via the use of the "fully expanded" conditions, which corresponds to an ideally expanded state when the plume static pressure relaxes to that of the ambient condition.

$$
q_{j}=\frac{1}{2} \gamma p_{a} M_{j}^{2}, \quad M_{j}=\left[\left\{\left(\frac{p_{0}}{p_{a}}\right)^{\frac{\gamma-1}{\gamma}}-1\right\} \frac{2}{\gamma-1}\right]^{0.5}
$$

When the parameters associated with the fully-expanded states are included, equation 5(b) above can be further expanded as:

$$
\frac{p_{f}^{\prime}}{p_{t}^{\prime}}=f\left(\frac{D_{e r}}{D_{e h}}, \frac{D_{j r}}{D_{j h}}, \frac{\alpha_{r}}{\alpha_{h}}, \frac{\beta_{r}}{\beta_{h}}, \frac{M_{j r}}{M_{j h}}, \frac{M_{e r}}{M_{e h}}, \frac{\left(p_{e} / p_{a}\right)_{r}}{\left(p_{e} / p_{a}\right)_{h}}, \frac{c_{j r}}{c_{j h}}, \frac{\rho_{j r}}{\rho_{j h}}, \frac{\rho_{e r}}{\rho_{e h}}, \frac{U_{j r}}{U_{j h}}, \frac{U_{e r}}{U_{e h}}, \frac{\left(J_{e} / J_{a}\right)_{r}}{\left(J_{e} / J_{a}\right)_{h}}, \frac{W_{e r}}{W_{e h}}, \frac{q_{f}}{q_{t}}, \frac{q_{j r}}{q_{j h}}\right)
$$

The parameter space is large, since many of the same variables had to be considered for both at nozzle exit and at fully-expanded conditions. To maximize the number of variables that can be closely matched within the available limit of the Helium supply, typically two different combinations of Helium and wind tunnel conditions were used to simulate one abort scenario. These were called the "nozzle-exit match" and the "q-ratio match" conditions.

“Nozzle-exit match": Following the guidelines from prior works (Section IIA above) various flow parameters from the nozzle exit plane of the rocket plume were matched in these set of run conditions. Although a reasonable match in the nozzle exit conditions was achieved using Helium, still there were some differences. In section IF of this paper a scaling law to account for these deficiencies are described. Another point to note is that to match the nozzle 
exit Mach number $\mathrm{M}_{\mathrm{e}}$ of the flight vehicle, the throat diameter of the Helium model had to be opened up more than the geometric scaling. These "nozzle-exit match" points required operating the Helium plume at the highest available temperature and pressure conditions.
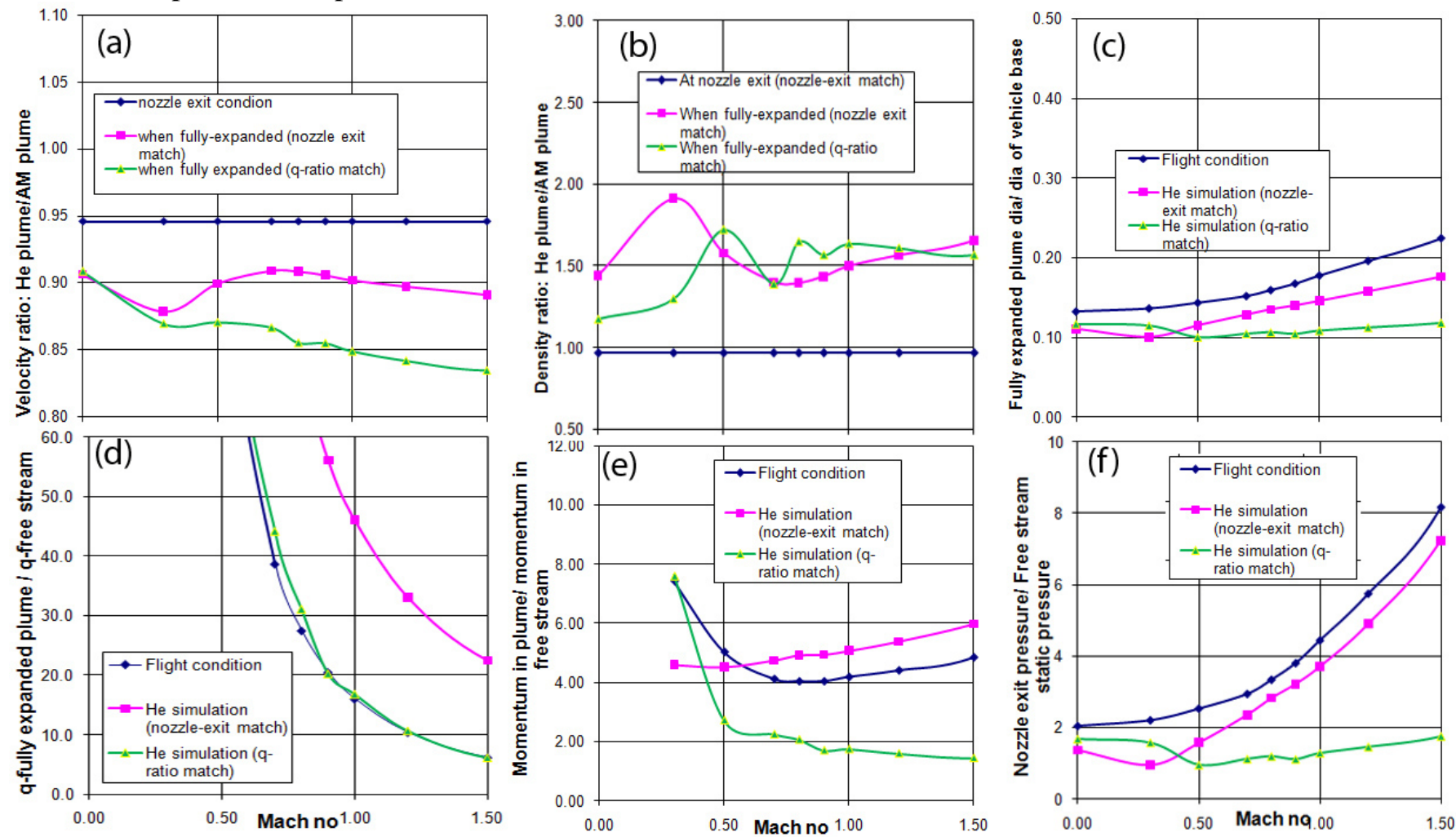

Fig. 4. Comparison of various acoustically-relevant parameters in full-scale aborts (occurring over a range of flight $\mathrm{M}$ ), and corresponding wind-tunnel simulations using "nozzle-exit match" and "q-ratio match": (a) plume velocity ratios: $\mathrm{U}_{\mathrm{eh}} / \mathrm{U}_{\mathrm{er}} \& \mathrm{U}_{\mathrm{jh}} / \mathrm{U}_{\mathrm{jr}}$; (b) plume density ratios: $\rho_{\mathrm{eh}} / \rho_{\mathrm{er}} \& \rho_{\mathrm{jh}} / \rho_{\mathrm{jr}}$; (c) Fully expanded plume diameter as a fraction of the LAV vehicle diameter; (d) q-ratio: $\mathrm{q}_{\mathrm{jr}} / \mathrm{q}_{\mathrm{f}} \& \mathrm{q}_{\mathrm{jh}} / \mathrm{q}_{\mathrm{t}}$; (e) momentum ratio: $\left(\mathrm{J}_{\mathrm{e}} / \mathrm{J}_{\mathrm{a}}\right)_{\mathrm{r}} \&\left(\mathrm{~J}_{\mathrm{e}} / \mathrm{J}_{\mathrm{a}}\right)_{\mathrm{t}}$; and (f) Nozzle exit pressure ratio; $\left(\mathrm{p}_{\mathrm{e}} / \mathrm{p}_{\mathrm{a}}\right)_{\mathrm{r}}, \&\left(\mathrm{p}_{\mathrm{e}} / \mathrm{p}_{\mathrm{a}}\right)_{\mathrm{h}}$.

"q-ratio match": To satisfy the need to match two q-ratios of equation (5b), a set of operating parameters were chosen such that the ratio of the dynamic pressures between the rocket \& the flight $q$ is maintained in the windtunnel simulation:

$\frac{q_{j r}}{q_{f}}=\frac{q_{j h}}{q_{t}}=q_{-}$ratio

The fluctuating pressure data from the wind tunnel are to be scaled by the above ratio to obtain the flight conditions. Compared to the "nozzle exit match," the "q-ratio match" required operating the wind tunnel freestream at higher dynamic pressure (i.e. Reynolds number) while lowering the Helium chamber pressure. On the upside, these data points required lesser amount of Helium; on the downside, the aerodynamic load on the sting holding the model became very high. Some of the high Reynolds number conditions at the highest Mach number settings of $\mathrm{M}=1.05$ and 1.2 could not be achieved due to excessive sting deflections. In such situations the tunnel Reynolds numbers were brought down to the acceptable sting deflections.

In addition to the above two conditions, additional "low Reynolds number" data points were taken for some Mach numbers to simulate higher altitude aborts. These points were taken with the highest possible Helium pressure and the lowest possible tunnel static pressure to maximize the plume expansion. The intention was to estimate the fluctuation level for aborts happening at Mach numbers beyond the range available in the present simulations. Only a limited number of such data points were obtained in this test.

The test was conducted at the NASA Ames Unitary Plan, 11-Foot Transonic Wind Tunnel where a host of abort conditions in the Mach number range $0.3 \leq \mathrm{M}_{\mathrm{t}} \leq 1.2$ were simulated. The original plan for the test was to cover a wider range of forward flights, up to $M=2.5$, but excessive costs caused a reduction in the scope of this test. Nevertheless, aborts occurring below the high transonic Mach number range are expected to provide the 
maximum pressure fluctuations over most of the vehicle. It was desirable to collect data at zero forward velocity (Pad abort condition); however, the possibility of permanent damage from the hot gas accumulation limited the lowest tunnel Mach to 0.3. At the upper end, the highest Mach number achievable in the empty tunnel is 1.45; however, during this test it was found that the large blockage caused by the gas-lines that supply Helium to the model, limited the maximum achievable Mach number to 1.2.

The angle of attack $\alpha$, and the side-slip angle $\beta$ were varied within $\pm 15^{\circ}$. The test was conducted at eleven different model attitudes. Basically one quadrant of the $\alpha-\beta$ plane was completely covered, and a few other attitude points at the other quadrants were obtained to check for the symmetry of pressure fluctuations. Changing the model attitude was not a straightforward process. The obstacle to overcome was to find a means to pass the hot Helium to the sting; since the gas temperature exceeded the maximum allowable temperature for the existing hollow strut of the 11-ft tunnel. A pair of insulated pipes was custom-built for each of the eleven model attitudes. Each pair supplied Helium from the bottom of the test section to the model sting, and had to be swapped to change the model attitude.

Developing the test matrix for the Helium plume condition followed a complex balance between what is desirable for an ideal match, the maximum-size of the Helium system possible to construct within the engineering and financial limit, and the upper limit of the wind-tunnel operations. A $6 \%$ scale model so that many components from a previous test could be recycled. The maximum plenum temperature for Helium of $700^{\circ} \mathrm{F}$ was limited by the carbon steel pipes used for delivery of hot Helium from the heater to the model, and also by the thermal stress limitations at the tunnel penetration. The system was built to provide a maximum Helium mass flux of 5.2lbm/s so that the total mass of Helium used remained within available resources. The amount of Helium used was a significant part of the total US west coast supply.

Figure 4 shows a comparison of various parameters achievable within the operational limitations of the 80AS test. Note that like the "nozzle exit match,” the "q-ratio match" also provided reasonably good correspondence of Mach number and plume velocity at the nozzle exit for all flight Mach numbers. Use of the two matching conditions improved correspondence in the fully-expanded conditions; however, differences are seen in parameters such as the fully expanded velocity, nozzle exit pressure ratio, momentum ratio and the fully expanded diameter. Once again the primary causes of these differences are the widely different $\gamma$ in He vs. rocket plume, and the limit on the maximum plume temperature usable in the wind tunnel. Nevertheless, it is expected that the use of scaling laws will account for many of these differences.

(a)

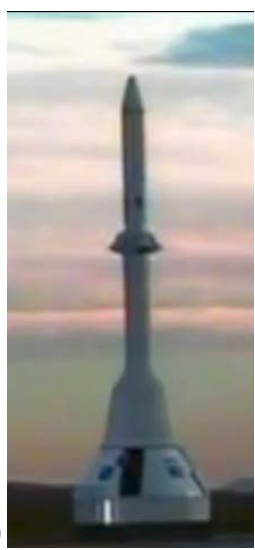

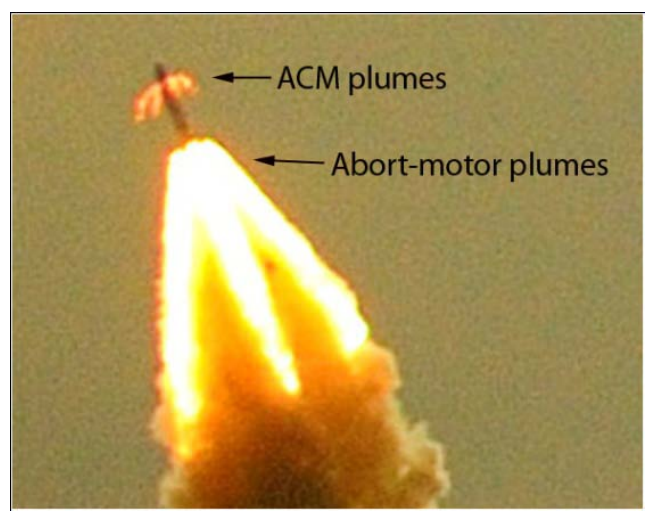

(b)

Fig 5. Photograph of the Pad Abort 1 vehicle (a) before flight, (b) on-flight.

\section{IE. MPCV test flight: Pad Abort I}

The Pad Abort 1 flight test took place on May 6, 2010 at White Sands Missile Range in New Mexico (fig 5). A fullscale, unmanned model of the LAV was tested to verify the different phases of the flight and recovery processes for an abort scenario initiated from a launch pad (Idicula et al 2009). In the very first phase of the flight, the abort motor was lit which made the vehicle to gain speed and altitude very quickly within a couple of seconds of motor operation. The outer surface of the vehicle was instrumented with 63 dynamic pressure transducers to measure the surface pressure fluctuations. Transducer data from the first couple of seconds of the flight were analyzed and compared with the hot-Helium data obtained from the present test. The flight data obviously contained changing conditions as the vehicle passed over a range of forward Mach number. Moreover, the PA1 vehicle was built based on an earlier design that used a slimmer outer mold line (fig $5 \mathrm{a}$ ), so the plumes were further away from the body 
surface. In spite of these differences, availability of the flight data provides a good opportunity to determine the strength and deficiencies of the Helium simulations.

\section{IF. Relationship to scale Wind tunnel data to Flight condition:}

In addition to testing a small- scale model, various flow parameters between the rocket plume and flight-stream cannot be perfectly matched in a wind tunnel test. Therefore, scaling laws need to be applied to the measured data. Observations made during the test showed that the pressure fluctuations are primarily plume dominated. The nearfield pressure fluctuations present in the plume shear layer are the primary contributor to the surface pressure fluctuations. These fluctuations are expected to be scaled by the dynamic pressure in the plume rather than any radiated acoustics fluctuations. Therefore, the standard dynamic pressure and Strouhal frequency based scaling rule should be applicable. The frequency is scaled using Strouhal number correspondence between the test and flight conditions:

$$
S t_{j r}=S t_{j h}, f_{r}=f_{h} \frac{D_{j h}}{D_{j r}} \frac{U_{j r}}{U_{j h}}
$$

The spectral levels (psd) are scaled assuming the same non-dimensional overall fluctuation levels $\mathrm{Cp}_{\mathrm{rms}}$, between the model and prototype. This leads to the following widely used relationship:

$$
\left(p s d_{f}\right)_{i}=\left(\frac{q_{j r}}{q_{j h}}\right)^{2} \frac{D_{j r}}{D_{j h}} \frac{U_{j h}}{U_{j r}}\left(p s d_{t}\right)_{i} \quad i=1,2, \ldots . \text { no of frquency bins (10) }
$$

Note that the dynamic pressure $q$ in the above relation corresponds to the fully expanded vales $\mathrm{q}_{\mathrm{j}}$ for the Helium and rocket plumes.

Recall that the presence of the flight stream and the plume stream brings two different dynamic pressures (q of the free-stream, and q of the plume) to the present problem. For the "q-ratio match" test points, scaling by the plume q, as shown in the above equation, automatically accounts for any difference in the free-stream q between the wind tunnel and flight conditions. For the rest of the test conditions, the ratio of the plume q is still used for scaling. The justification is that the flow field is primarily dominated by the plume rather than by the flight stream.

\section{THE TEST APPARATUS}

After studying the suitability of different large wind-tunnel facilities, the Unitary Plan 11-Ft Tunnel was selected primarily because of the wide Reynolds number range available for each Mach number condition. The wind tunnel is a closed circuit, single return, variable density, continuous flow facility that has an 11'X11' test section. The technical details of the tunnel can be found in its website and in reference 16. The tunnel was operated in the Mach number range of $0.3 \leq \mathrm{M} \leq 1.2$ and in the Reynolds number range of $2 \mathrm{e} 6 / \mathrm{ft} \leq \mathrm{Re} \leq 5 \mathrm{e} 6 / \mathrm{ft}$. The glass walls of the test section allowed for good shadowgraph visualization in spite of the presence of the axial slots for wall suction (to minimize shock reflection). Additionally, an infra-red camera, mounted on the ceiling, was used to visualize the top part of the model. The primary goal of the IR imaging was to determine the extent of plume impingement on the model surface, associating impingement with changes in pressure fluctuations over the model.

Two oxygen-sensors were mounted close to the test section to monitor the Helium concentration inside the tunnel. As a set of test points were collected Helium accumulated in the closed-circuit wind tunnel. To minimize this accumulation the tunnel was periodically purged after a set of data points (typically 5 to 12) was collected. The maximum volume fraction of Helium reached $15 \%$ for some test points; however, the resulting impact on $\gamma$ and the tunnel Mach number was found to be very small. The biggest impact of Helium on the tunnel operation was a reduction of the free-stream Reynolds number by a maximum of $10 \%$ from the set condition. This level of variation was deemed acceptable for the present data analysis.

\section{IIa. The LAV model and the dynamic pressure sensors}

The 6\%-scale model accurately represented all details larger than $1 / 2$ ” on the full-scale vehicle. It included four symmetric abort motor nozzles. The model was held by hollow sting attached to the main strut of the test section. The hot Helium gas was brought through the floor of the test section to the sting via two 2" diameter pipes. The gas then flowed upstream through the inside of the sting to a local plenum at the lower-tower. Forward of the local plenum was the nozzle section where the gas made a $160^{\circ}$ turn to exit through the four nozzles. The model had stainless-steel skins and active interior cooling to ensure the survival of various instrumentations. Various other details of the model can be found in a separate report (Fong 2011). 


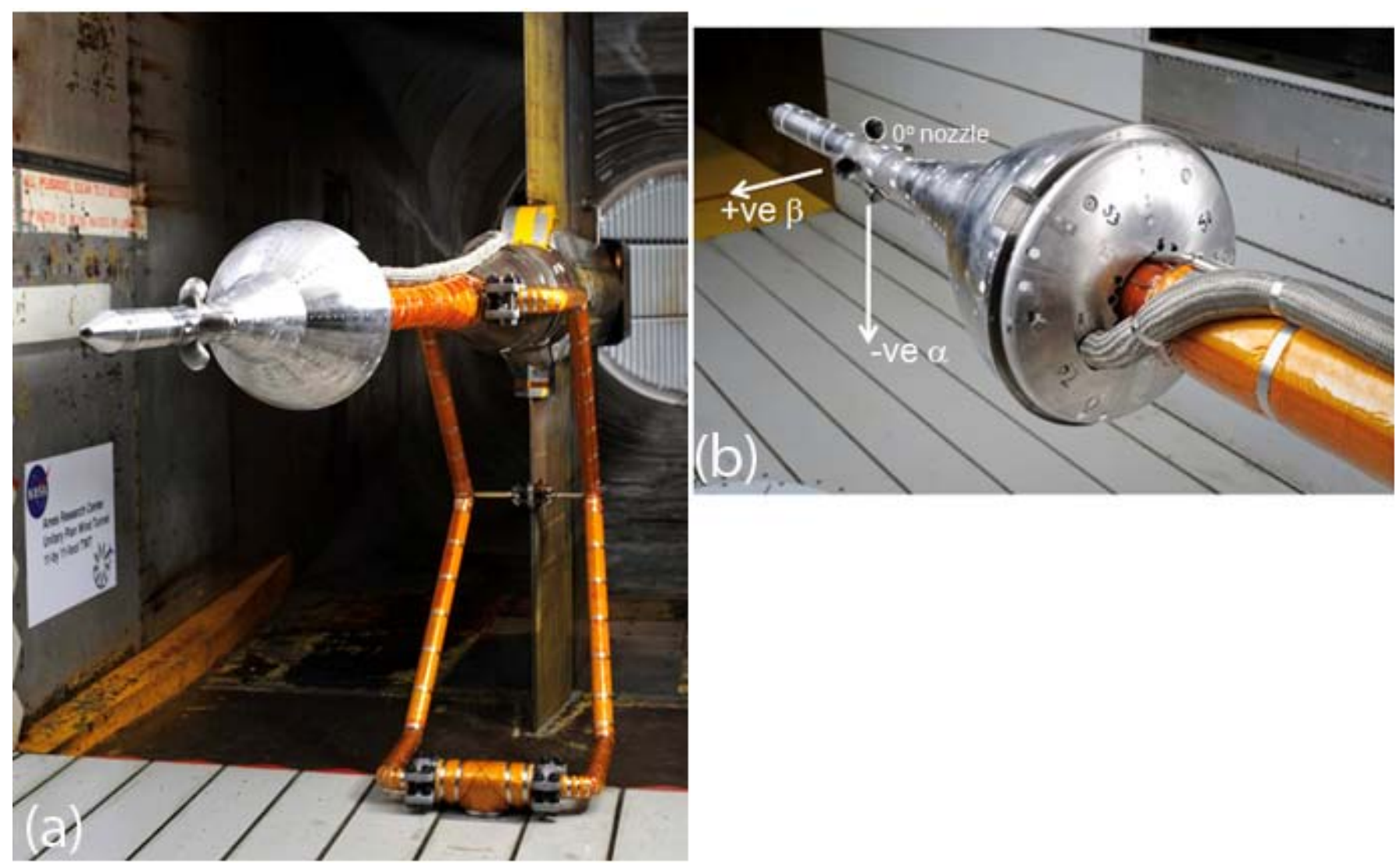

Fig 6. Photograph of the model inside the 11' test section; (a) view from upstream: the orange pipes brought hot Helium from underneath the tunnel to the model sting; (b) view from downstream.
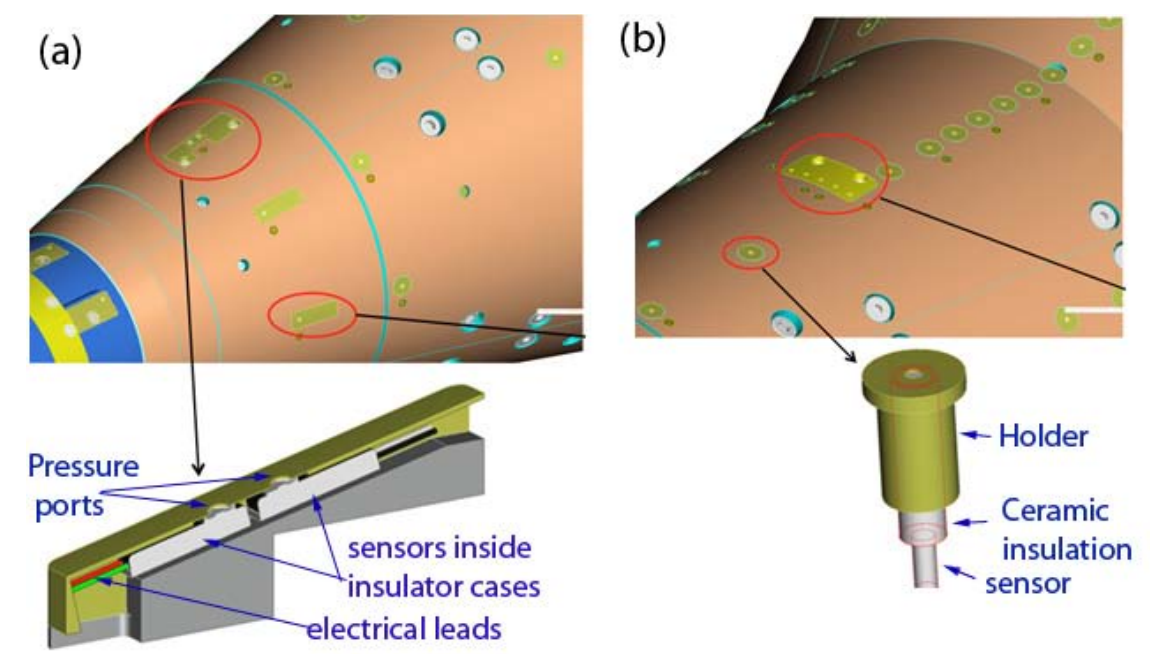

Fig 7. Details of the kulite mount; (a) two horizontally-mounted sensors; (b) one vertically mounted sensor.

The model was heavily instrumented with 237, high-temperature, 50psig sealed gauge, dynamic pressure sensors (Kulites). All but 32 of the sensors are of type XCEL-10-100-50FG and were mounted perpendicular to the skin surface. The remaining 32 were of type LLHT-072 and were mounted in slots horizontal to the surface, in tight places where perpendicular mounting was impossible. They were mostly mounted on the lower tower, downstream of the nozzle, and on the subsequent straight and conical sections. Because the horizontal sensors were mounted directly in the surface of the nozzle section with high temperature gas flowing through the center, the failure rate was found to be far higher than the perpendicularly-mounted counterparts. Nominally the Kulites were recessed by 0.007" from the surface. Such a recess-mount produced a small, yet important cavity between the sensor tip and the model surface. The cavity was expected to act as a Helmholtz resonator and to create a spurious hay-stack peak at high-frequency. An examination of the spectral data collected without the Helium flow and at very low tunnel 
speed indeed showed the presence of these peaks. However, the resonance peak was found to be a function of the flow speed over the sensor cavity. Data taken without the Helium flow but with an increasing wind tunnel speed showed a progressive lowering of the amplitude and an increase in the frequency of the resonance. The peaks became either weak or entirely absent when the Helium plumes were turned on. This observation of weakening of the resonance peak with increasing tunnel speed is consistent with observations made by Hanley (1975).

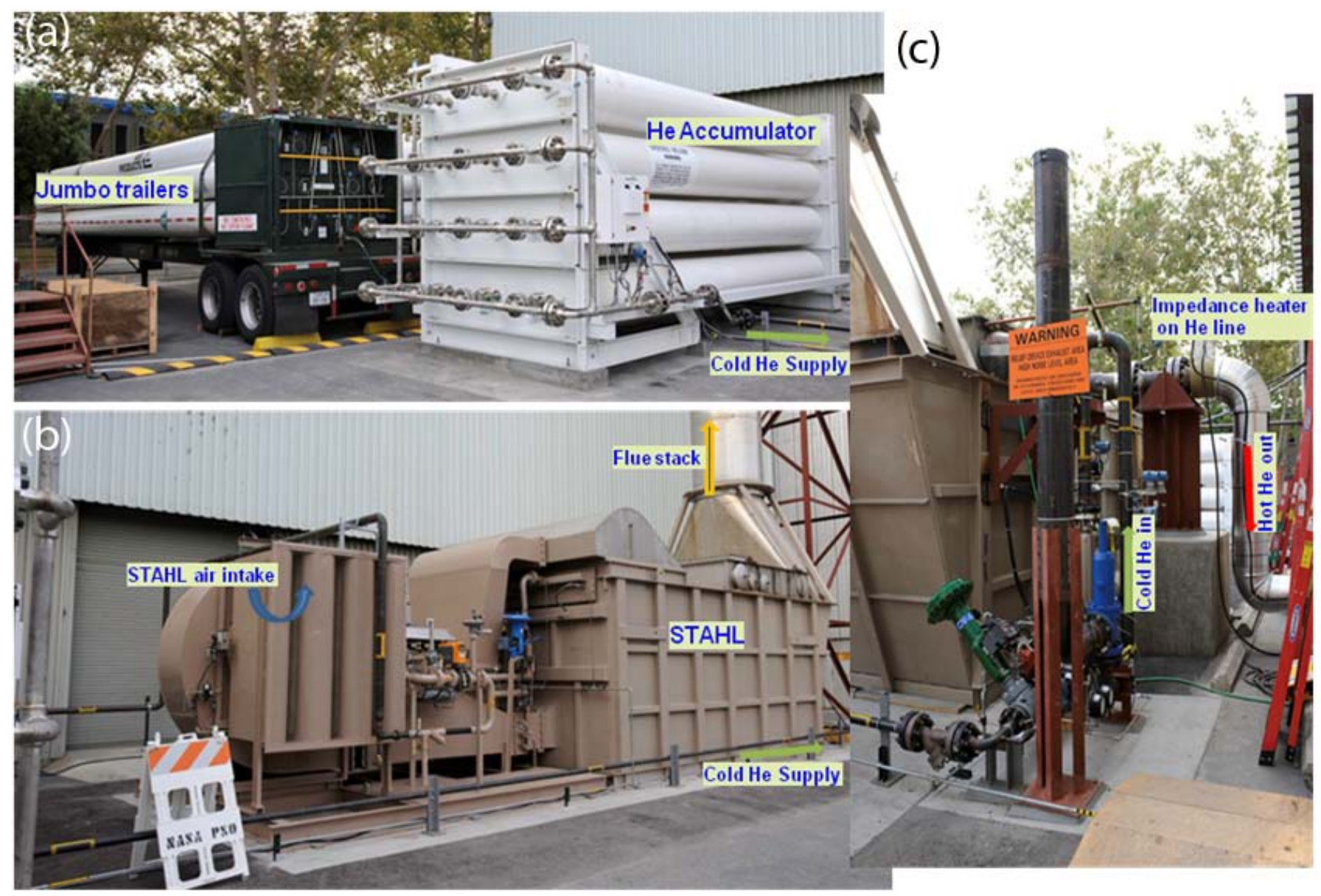

Fig 8. A photographic tour of the Helium delivery system. (a) Helium arrives via jumbo trailers which are connected to an accumulator. (b) The accumulator supplies this Helium to the STAHL heater which uses natural gas to heat up air which in-turn passes over the heat-exchanger coils. (c) Cold Helium enters the heat-exchanger via a bare pipe, while the hot Helium goes out via pipes that are induction-heated to 750F and insulated.

\section{IIb. The hot Helium delivery system:}

The delivery system was capable of providing hot Helium at $700^{\circ} \mathrm{F}$ and at 610 psia pressure at the plenum chamber inside the model. Central to the Helium-system was a large heater. After an exhaustive search, and review of different options, a natural gas fired, 44M BTU/hr (13MWh), "STAHL" heater was selected for the test. In fact, the scope of the test revolved around the capacity of such a heater. The heater was transported from the NASA Glenn Research Center and was slightly modified to suit the test. Natural-gas was burned in an airflow supplied by a blower. The heated air was then circulated over a large heat-exchanger coil through which the Helium gas flowed. Helium came to the test facility via jumbo trailers (fig 8). Typically two or three trailers, each supplying about $1100 \mathrm{lbm}$ of Helium, were used for each day of testing. The trailer outlets were found to be too small to supply the required mass flow rate; therefore, an accumulator was built to temporarily store Helium before passing to the heater. When required, Helium flowed from the accumulator to the heater. The heat-exchanger coils of the STAHL were pre-heated to a fixed set point. The large mass of steel in the heat-exchanger pipes acted as thermal capacitors storing enough to quickly bring Helium to the desired temperature. The heated Helium flowed through a long pipeline which penetrated the wind-tunnel pressure-shell and reached the floor of the test section. A large part of this pipe, upstream of tunnel penetration was pre-heated using an electrical impedance heater to maintain the gas temperature. Two smaller diameter pipes delivered Helium from the floor of the test section to the sting holding the 
model. As noted earlier, the hot Helium flowed through the hollow sting, and then a small settling chamber inside the lower-tower of the LAV model, before exhausting through the four nozzles. The entire helium delivery system including all control devices and human-machine interface were custom-built for this test. A second part of the gas system was an unheated, high-pressure, air supply used for cooling. The model needed to be cooled for any repair and inspection work, as well as to change its attitude. The high pressure air was also used to continuously cool the model cavity that held various instrumentations.

\section{IIc. The test operation:}

The test was divided into two parts: an integrated system test to check-out the elaborate control system, and the final completion of the test matrix. Dynamic pressure data were collected over both phases to maximize Helium utilization. The first part of the test provided mostly long data records with progressively increasing plume total temperature and pressure, which may be used to verify scaling laws and other purposes. Data from the second part of the test are presented here. Typically a test would start when the STAHL reached a preset temperature. At that point the wind-tunnel was brought to the desired Mach and Reynolds number condition, and a volley of hot Helium lasting for about 30s was passed to the model via the heater. Typically a large part of heat from this first volley was absorbed by various pipes and valves, and the temperature at the model plenum failed to reach the desired set limit. The first volley was followed by a second one within a minute. The dynamic data acquisition was started when the plenum pressure and temperature reached target values within an acceptable tolerance. All dynamic pressure sensors were simultaneously sampled at $102,400 / \mathrm{s}$ for 5 s durations. The Helium supply was stopped at the end of the data acquisition. The wind tunnel conditions were changed to the subsequent test point, typically within a few minutes, and the next volley of Helium was passed. This operation was continued until the Helium pressure in the trailer and the accumulator fell below the usable limit. A typical day used 1500 to 2500lbm of Helium and produced 10 to 15 test points. It needs to be pointed out that every Helium test point was preceded by a no-flow point when the wind tunnel was operated at the desired $\mathrm{M}$ and Re condition yet no Helium was passed to the nozzle.

\section{RESULTS AND DISCUSSIONS}

A large amount of data and images were collected from this test but only a glimpse of this data-base could be presented in this paper. Figure 9 shows a simulated abort at the lowest tunnel Mach of 0.3 where the nozzle-exit conditions of the Helium plume were closely matched to that expected in the full-scale vehicle. The quality of the shadowgraph images of the Helium plumes were better than expected. A comparison of the time averaged photograph of fig 9(a) with the CFD generated rocket plume of fig 1(a) shows that the distance of the plumes from vehicle surface are comparable; the primary difference is a shorter length of the internal shock-cell structure for the Helium case. This discrepancy is due to the difference in the ratio of the specific heats as discussed earlier, and may not have much bearing to the surface pressure fluctuations. The short exposure photograph of fig 9(b) provides a more insightful description. The acoustic radiation patterns are visible away from the plume. Of more importance is the indication that the outer edge of the plume shear layer interacts with the Ogive part of the model even at this low forward speed. The primary shear layer is still away from the surface; yet the outer edge scrubs the vehicle surface. Some of the higher pressure fluctuations in this test were measured in such situations.

Part (c) of this figure shows the distribution of the normalized, overall, pressure fluctuations, $\mathrm{Cp}_{\mathrm{rms}}=$ $\mathrm{p}_{\mathrm{rms}}^{\prime} / \mathrm{q}_{\mathrm{jh}}$, on the model surface. The maximum overall level is about $2 \%$ of the plume dynamic pressure, which is very high in these high-velocity plumes. The footprints of the four plumes are distinctly visible as regions of higher levels. Note that the interpolation process used in the plotting routine, over the regions where sensor loss occurred, gave the discontinuous appearance in some part of fig 9(c).

The normalized psd from two selected groups of sensors are shown in part (d) of fig 9. The locations of the sensors are shown in Table III. For a consistent comparison, spectra measured from the same sensors are shown in all similar figures presented in this paper. The first group of sensors lay just underneath the $0^{\circ}$ plume (top plume in the shadowgraph), and the second group at $45^{\circ}$ from the first, between two plumes. The narrow-band spectra calculated from the time-traces with frequency resolution $\Delta \mathrm{f}$ are normalized using the fully-expanded dynamic pressure and Strouhal frequency:

$$
\text { normalized psd: } \frac{p^{\prime 2}}{q_{j}^{2}\left(\frac{\Delta f D_{j}}{U_{j}}\right)}=\frac{(p s d)_{i}}{\left(q_{j h}^{2}\right)\left(D_{j h} U_{j h}\right)}
$$


Note that the equality of the above non-dimensionalized spectra between the Helium plume and the abort-motor plume is the basis for the scaling relationship of equation (10). The power spectra from the two groups of sensors are distinct. Sensors from under the plume have peaks around St $\sim 0.2$ and have higher levels; these sensors are relatively unaffected by the free-stream. On the other hand, spectra from sensors between two plumes have "flattop” shape and contain lesser energy.

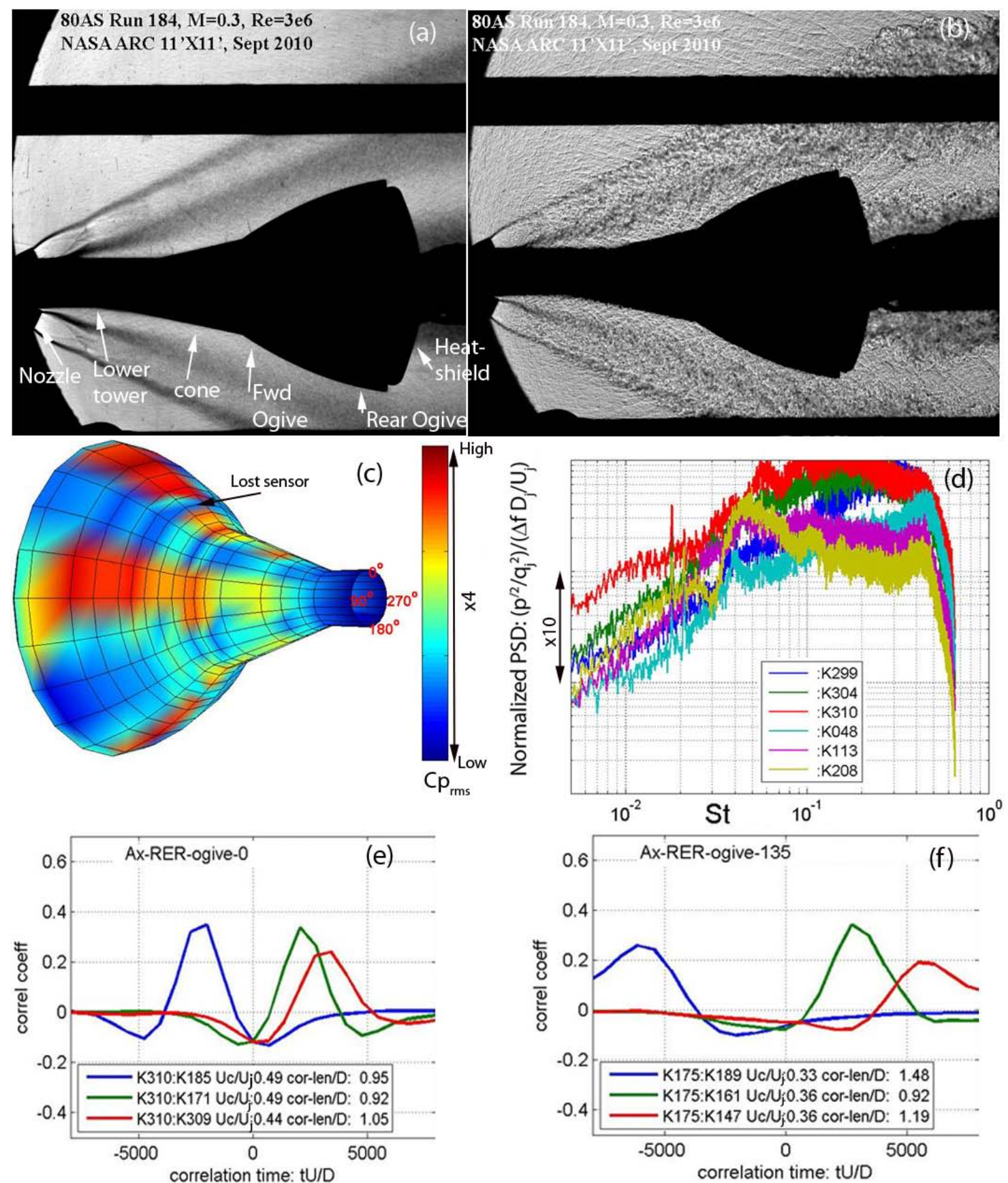

Fig 9. Wind-tunnel and Helium plume simulation of an abort occurring at a flight Mach $=0.3$ and vehicle attitude: $\alpha=\beta=0^{\circ}$. (a) Time-average \& (b) short-exposure shadowgraph images of the Helium plumes over the model; (c) distribution of the overall level of fluctuations over the model; (d) normalized spectrum of pressure fluctuations; (e) correlation among sensors lying underneath a plume axis and, (f) similar correlation among sensors in-between two plumes. Tunnel $\mathrm{Re}=3 \mathrm{e} 6 / \mathrm{ft}$. The horizontal bars in the shadowgraph images are the locations for the suction slots on the tunnel wall. One of the bars lay along the centerline of the model in the shadowgraph images.

Table III: locations of Kulites shown in psd plots (fig 9a shows different zones on LAV):

\begin{tabular}{|l|l|l|l|l|l|}
\hline K299 & K304 & K310 & K048 & K113 & K208 \\
\hline
\end{tabular}




\begin{tabular}{|l|l|l|l|l|l|}
\hline $\begin{array}{l}\text { Under plume, } \\
\text { Cone }\end{array}$ & $\begin{array}{l}\text { Under plume, } \\
\text { Forward Ogive }\end{array}$ & $\begin{array}{l}\text { Under plume, } \\
\text { Rear Ogive }\end{array}$ & $\begin{array}{l}\text { Between } \\
\text { plumes, Cone }\end{array}$ & $\begin{array}{l}\text { Between Plumes, } \\
\text { Forward Ogive }\end{array}$ & $\begin{array}{l}\text { Between Plumes, } \\
\text { Rear Ogive }\end{array}$ \\
\hline
\end{tabular}

The normalized correlation coefficients between pairs of sensors, separated in the axial direction, are shown in parts (e) and (f) of fig 9. The convection velocity was measured from the time delay in the correlation peak and from knowledge of the sensor-separation. The values were then normalized by the fully expanded plume velocity. The correlation lengths were measured from the magnitudes of the spatial correlation and the separation distance between sensors (Panda 2006). As expected, the convection velocities were found to be faster underneath the plume, and somewhat slower in between two plumes. Nevertheless, the absolute values are far-higher than the ambient sound speed or the speed of the free-stream flow. This was found to be true even at higher free-stream Mach number conditions. This observation confirms that the pressure fluctuations on the vehicle surface is dominated by the very near-field fluctuations of the jet shear-layer; the "Mach-wave" type acoustic radiation is of secondary importance. The correlation lengths are also comparable to those found in typical plume shear layers (Panda 2006).
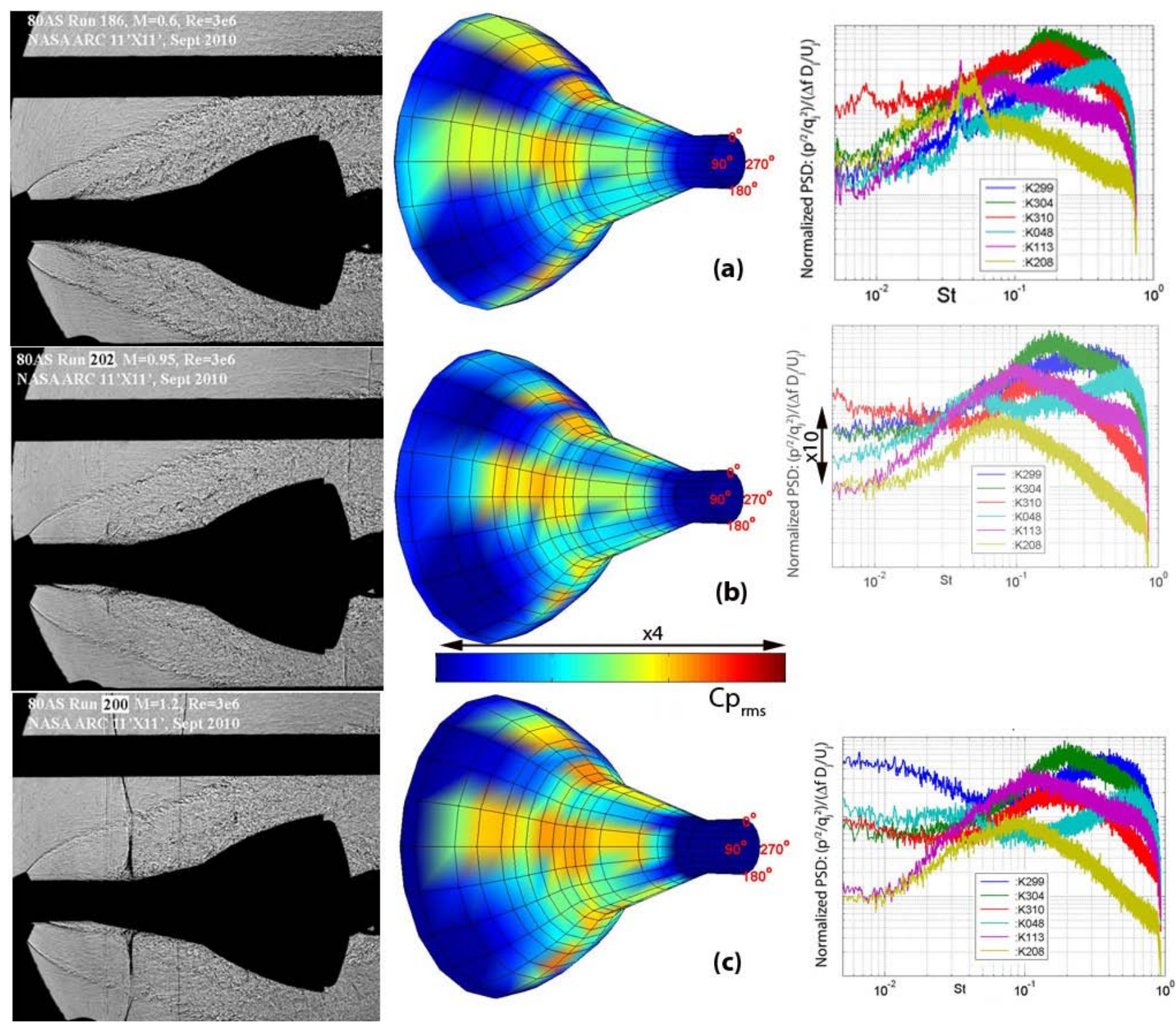

Fig 10. Shadowgraph image, distribution of the overall level of fluctuations and normalized spectra from indicated sensors for flight Mach numbers (a) $\mathrm{M}_{\mathrm{t}}=0.6$, (b) $\mathrm{M}_{\mathrm{t}}=0.95$, \& (c) $\mathrm{M}_{\mathrm{t}}=1.2$; for all cases Re=3e6/ft and $\alpha=\beta=0$.

\section{IIIA. Effect of increasing flight speed}


An abort initiated at a higher flight Mach number also means that the abort is occurring at a higher altitude. In the transonic wind tunnel altitude is simulated by lowering the ambient static pressure with the increased flight speed. Additionally, to bracket all possible altitude conditions for a given flight Mach, the tunnel Reynolds number was also varied. A glimpse of this data-base is shown in fig 10. For a better comparison the plots of fig 10 need to be compared with those of fig $9(\mathrm{M}=0.3$, everything else remaining the same). As expected, the shadowgraph images show an increase in the plume diameters with an increase in the flight speed. The lower-tower region, just downstream of the nozzle exit, was always scoured by the plume and showed the lowest level of fluctuations. The fluctuation levels, however, increased significantly over the cone and the ogive regions where the shear layers of the plumes were lifted off the body surface. The plume souring at the rear part of the ogive once again was accompanied by a lowering of the levels. At the transonic $M=1.2$ condition, shock waves set up on the vehicle (fig 11c); however, the accompanying increase in fluctuation levels were relatively small. An examination of the spectra show a particularly important feature: progressive increase in the low frequency content from regions under the plume. The structural elements of the vehicle are expected to be more responsive to the low frequency excitations.
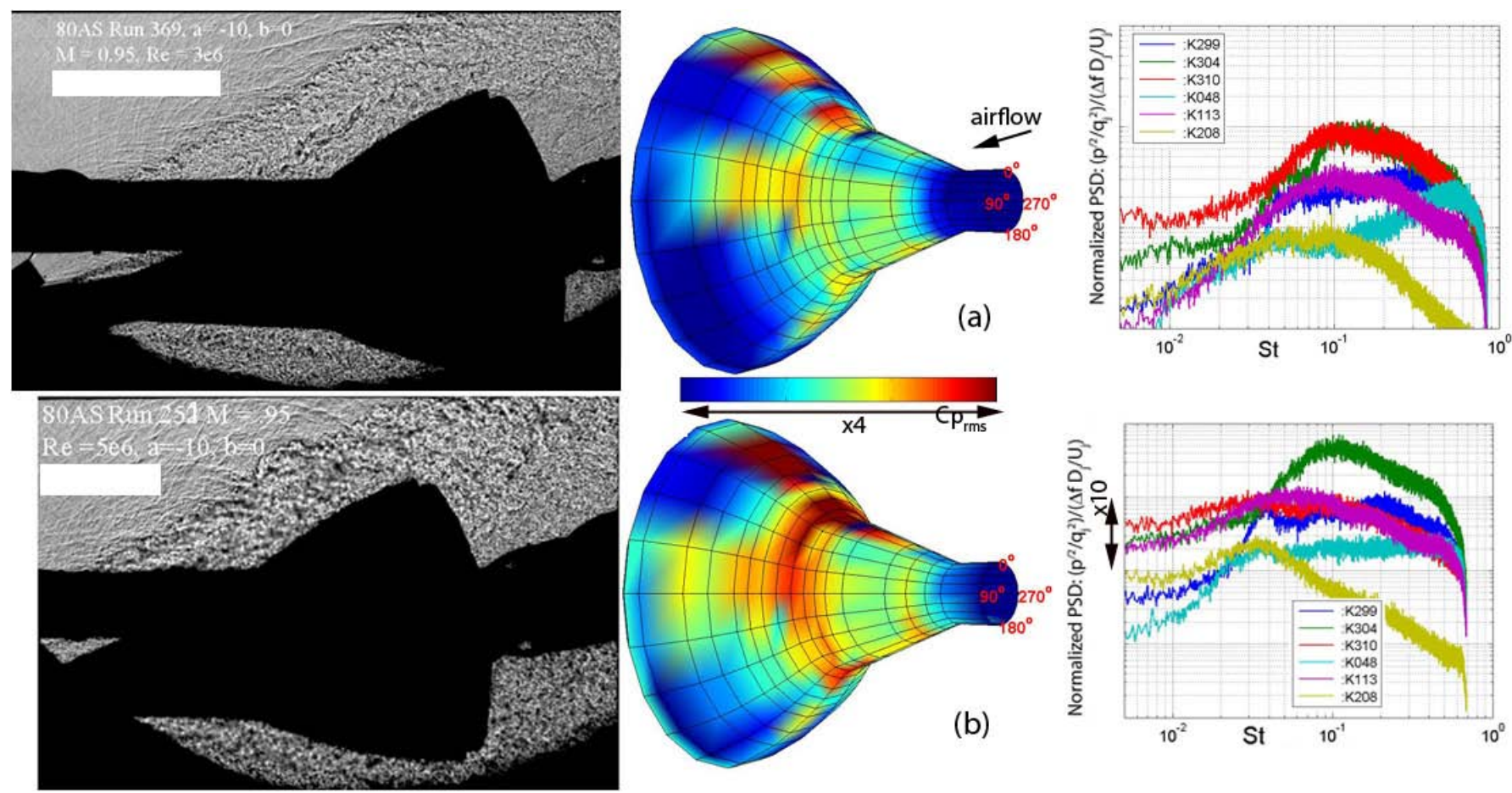

Fig 11. Shadowgraph image, distribution of the overall level, and spectra of pressure fluctuations for (a) Nozzle exit match condition $(\mathrm{Re}=3 \mathrm{e} 6 / \mathrm{ft})$, and (b) q-ratio match condition $(\mathrm{Re}=5 \mathrm{e} 6 / \mathrm{ft})$. Helium pressure for (b) is $60 \%$ of that used for (a); common to both: $\mathrm{M}_{\mathrm{t}}=0.95, \alpha=-10^{\circ}, \beta=0^{\circ}$.

\section{IIIB. "Nozzle-exit match" vs. "q-ratio match"}

As mentioned earlier, there were at least two test points taken for each abort condition. The first one matched the plume conditions at the nozzle exit, and the second one matched the ratio of the dynamic pressures in the freestream and in the fully expanded plume (equation 8). The latter required lowering of the helium supply pressure and an increase in the free-stream static pressure. Figure 12 shows a comparison between two such cases for one of the abort simulations. The particular abort simulation was at an angle of attack of $-10^{\circ}$ which destroyed the four-fold symmetry seen in the earlier plots. The fluctuation levels on the windward side were found to be higher than the leeward side. Nevertheless, the q-ratio match condition was found to produce more intense fluctuations in spite of a $40 \%$ lower thrust from the plume. The plumes from the "q-ratio matched" condition did not grow as large as that from the "nozzle-exit match," which also implied that the inner edge of the plume remained unattached to the vehicle surface. It is believed that the reduced impingement has caused an increase in the level of fluctuations.

\section{IIIC. Comparison with flight data from Pad Abort 1:}

As the abort motor was lit, the PA1 vehicle quickly gained speed and altitude. Therefore, the flight data is transient and included the influence of a broad range of forward Mach number. The Kulite time-traces over a a 
flight Mach number range of $0 \leq \mathrm{M}_{\mathrm{f}} \leq 0.65$ were used to calculate the overall levels and spectra of surface pressure fluctuations. The wind-tunnel data, on the other hand, were stationary and were collected at fixed Mach number intervals. In fig 13 the overall levels measured from the PA1 flight were compared against two Helium test points: at $\mathrm{M}_{\mathrm{t}}=0.3$ and 0.6. Each plot shows the distributions of $C \mathrm{p}_{\mathrm{rms}}$ on unwrapped vehicle surfaces. The encouraging part is that the Helium data nicely brackets the flight measurements. One interesting difference is the relatively smaller variation between locations underneath the plume and between plumes in the PA1 data. This is attributed to two additional features of the flight data absent from the Helium simulation. First, the PA1 vehicle maintained a small non-zero $\alpha$ and $\beta$. As seen earlier, non-zero vehicle attitude makes the plume to sway from a straight path, which can lead to a smearing of the sharp peaks and valleys. Second, in the actual flight Attitude Control Motors (ACM) were lit at the top of the vehicle (fig 5a) when the abort motor was burning. The plumes of the ACM solid-rockets are expected to add turbulent fluctuations to the incoming stream and can increase the pressure fluctuations in the relatively quieter between plume regions.

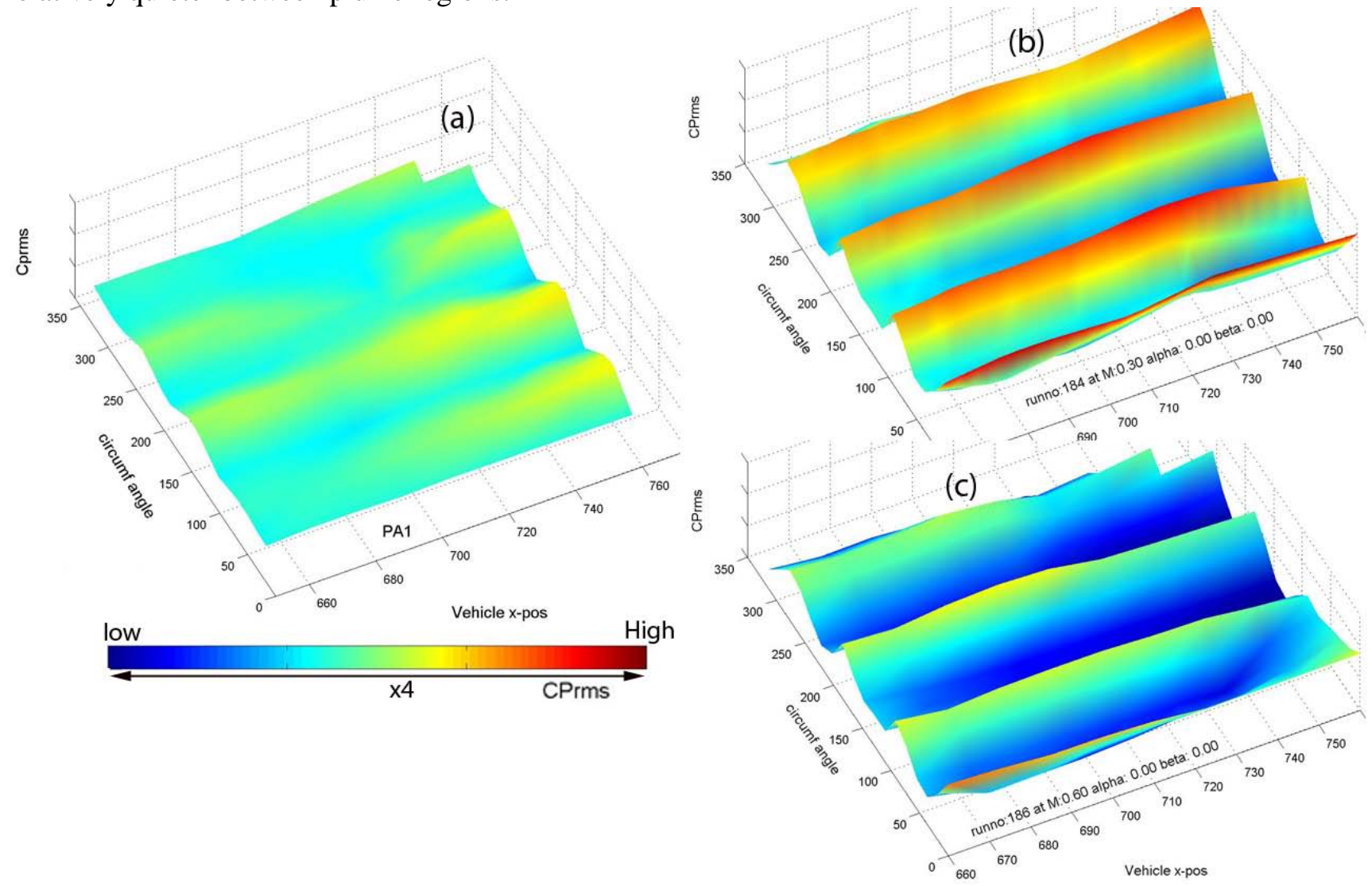

Fig 12. A comparison of the overall surface pressure fluctuations measured in (a) PA1 flight, (b) hot-Helium simulation at tunnel $\mathrm{M}_{\mathrm{t}}=0.3$; (c) hot He at $\mathrm{M}_{\mathrm{t}}=0.6$.

A sensor by sensor comparison of the fluctuation spectra is shown in fig 13 . Since the flight data is an average over a range of Mach numbers, spectra collected from the wind tunnel simulations over the same Mach range for both the "nozzle-exit match" and "q-ratio match" conditions are co-plotted. In spite of some finer differences, the spectral shapes are in general similar. For sensors directly under the plume axis the PA1 spectra are bracketed by the Helium simulation. The primary difference is seen in the high-frequency end $\mathrm{St}>0.1$, where the Helium plume appears to be noisier than the abort-motor plume. It is believed that some of the features of the rocket plume, such as the presence of the solid particles, and the afterburning of the fuel in the plume, that are absent in the Helium simulation are responsible for this difference. An examination of the prior comparison by Morgan and Young (1963) from static firing tests also indicates similar differences. Spectra from locations inbetween plumes in fig 14(c) and (d) show that the PA1 levels are higher than the Helium simulation. This however may have to do with the non-zero attitude flight angles and the presence of the ACM discussed earlier. 

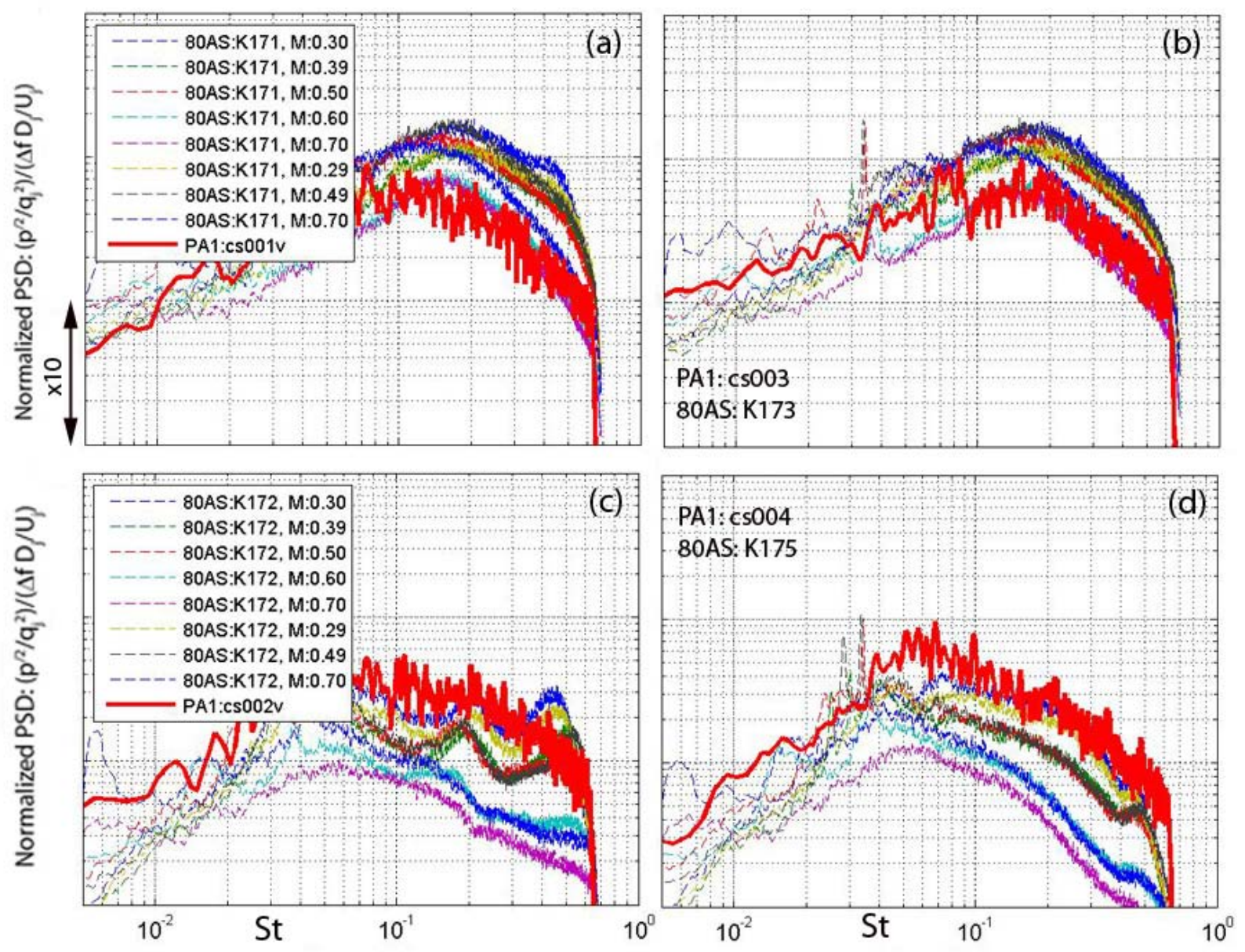

Fig 13. A comparison of the normalized spectra from indicated corresponding sensor on PA1 and the hot-Helium simulation (80AS); (a), (b) sensors under the plume axis; (c), (d) sensors between two plumes.

\section{SUMMARY AND CONCLUSION}

Helium gas heated to $700^{\circ} \mathrm{F}$ was used to simulate the pressure fluctuations created by the firing of the abort-motor on the surface of the Launch Abort Vehicle (LAV) over a wide range of flight Mach numbers $0.3 \leq \mathrm{M} \leq 1.2$ and vehicle attitudes: $\pm 15^{\circ}$. Compared to other gases, Helium provided the best match of the acoustically relevant parameters such as the sound speed, density, and velocity of the solid-rocket of LAV. Helium also provided the practicality of test operations, and a cost-effective means of creating 80 different abort scenarios in a wind tunnel facility.

Computational fluid dynamic simulations, and shadowgraph images taken from the test indicated that the surface pressure fluctuations on the vehicle are primarily dominated by the hydro-dynamic fluctuations present in the shear layer of the plumes. Such fluctuations are expected to be scaled by the fully-expanded dynamic pressure. The present application involving high forward velocity brought about a large parameter space for matching the present wind tunnel simulation with the actual flight conditions. In a nominal flight, where plume effects are absent, the ratio of dynamic pressure in the wind tunnel stream to that in the flight stream are used to scale model scale data. The presence of the abort plumes introduced a second ratio: the dynamic pressure in the Helium plume to that in the abort motor plume. To reasonably satisfy a multitude of different matching parameters, two different Helium simulations were used to replicate one abort scenario. The "nozzle-exit match" conditions reasonably replicated the nozzle exit condtion of the abort motor, and were used in the past small-scale similarity studies. The new "q-ratio match" conditions allowed for using one scaling equation to include the effects of the different dynamic pressures in the plume and the free-stream. 
The test was conducted in the NASA Ames Unitary Plan 11-foot Transonic Wind Tunnel. A custom hot Helium delivery and control system was designed and built for this purpose. The central element of the system was a large natural gas heater supplied by the NASA Glenn Research Center. The heater was connected to jumbo trailers of Helium via an intermediate accumulator. The hot Helium gas was passed to the model via pipes that penetrated the tunnel pressure shell. Most of the pipes were kept hot via impedence heaters. A 6\% scaled model of the Launch abort vehicle, that can withstand the cyclical temperature fluctuations, and instrumented with 237 dynamic pressure trasducers, was also built for this test.

Shadowgraph images collected from the test showed the locations of the plumes at different flight Mach numbers, ambient static pressures and vehicle attitude conditions. It was observed that the plumes grew in diameter with an increase in the flight Mach number, and increased scrubbing of the vehicle surface. Interestingly, an increase in scrubbing was accompanied in general by a reduction in the level of pressure fluctuations. This indicates that for the same attitude, a pad abort will experience higher level of fluctuations than a higher altitude abort. The spectra of fluctuating pressure had similar shapes seen in the low speed plume. An effect of an increase in the flight speed was found to be a progressive increase of the low frequency part of the spectra.

The scaled up wind tunnel data were compared with those obtained from the Pad Abort 1 (PA1) flight test. The acoustic fluctuations on the unmanned LAV surface was measured using dynamic pressure sensors. In spite of various differences in the vehicle shapes, the absence of other control motors in the model test, and the transient flight condition versus steady-state simulation, it was found that the Helium data provided very reasonable comparison with the flight data. The primary difference is a richer highfrequency content of the Helium spectra. It is conjectured that some of the unavoidable differences between a solid rocket plume and a Helium plume, such as the absence of solid particles and the afterburning of fuel, are responsible for this differnce. Neverthess, data obtained from this unique, one of a kind, endeavor will provide aeroacoustics environment for the design and qualification testing of the Launch Abort Vehicle and many of its sub-systems, which are meant to save astronauts lives.

\section{Acknowledgement}

We are thankful to a very large number of team members whose combined efforts, problem-solving skills and dedication have made this test possible.

\section{Reference:}

1. Kinzie, K. W. \& McLaughlin, D. K. 1999 “Measurement of supersonic Helium/Air mixture jets,” AIAA J. vol. 37, no. 11.

2. Doty, M. J. \& McLaughlin, D. K. 2001 "Two-point correlations and acoustic measurements of high-speed jets," AIAA paper 2002-2553

3. Morgan, W. and Young, K (Boeing), March 1963, "Studies of Rocket Noise Simulation with Substitute Gas Jets and the Effect of Vehicle Motion on Jet Noise", Tech. Doc. Rep. no. ASD-TDR-62-787.

4. Tam, C. K. W., and Tanna, H. K., "Shock Associated Noise of Supersonic Jet from Convergent-Divergent Nozzle,” Journal of Sound and Vibration, Vol. 81, No. 3, 1982, pp. 337-358

5. Eldred, K.M., “Acoustic Loads Generated by the Propulsion System”, NASA SP-8072, June 1971.

6. McInerny, S., "Rocket Noise - A Review”, AIAA 13th Aeroacoustics Conference, Oct. 22-24, 1990, Tallahassee, FL.

7. Greska, B., Krothapalli, A., Horne, W. C. \& Burnside, N., May 2008, “A Near-Field Study of High Temperature Supersonic Jets”, AIAA-2008-3026, 14th AIAA/CEAS Aeroacoustics Conference, Vancouver, BC.

8. Greska, B., \& Krothapalli, A. 2009 "Simulation of Launch Abort System Exhaust Plumes with Downstream Surfaces, Part II Heated Helium Plume Test,” report submitted to NASA Ames Research Center.

9. Ffowcs Williams, J. E., 1965, "Surface-pressure fluctuations induced by boundary-layer flow at finite Mach number,” J. Fluid Mech. Vol. 22, part 3, pp. 507-519. 
10. Pelanti, M. \& Leveque, R. J., 2006 "High-resolution finite volume methods for dusty gas jets and plumes," SIAM J. Sci. Comput.

11. Marble F. E., 1970, “Dynamics of Dusty Gases,” Ann. Rev. Fluid Mech., vol.2, pp. 397-446.

12. Chan, Y. Y., \& Westley, R. 1973, “Directional acoustic radiation generated by spatial jet instability,” CASI transaction, vol. 6, pp. 36-41.

13. Papamoschou, D. 2007 “Acoustic simulation of coaxial hot air jets using cold Helium-air mixture jets,” J. Propulsion \& Power, vol. 23, no. 2, pp. 375-381.

14. Coirier, W. J., 2009, “80-AS Aero-acoustics CFD support update,” internal report presented to the CEV Loads and Dynamics group.

15. Idicula, J., Williams-Hayes, P., Stillwater, R., Yates M., 2009 “A Flight Dynamics Perspective of the Orion Pad Abort One Flight Test,” AIAA paper 2009-5730.

16. "Unitary plan wind tunnel - $11 \mathrm{ft}$ transonic wind tunnel- standard operating procedures," document no. A327A7691-XM1, prepared by the technical publications for the wind tunnel operations division, NASA Ames Research Center, April 2006.

17. Fong, R., 2011 80AS test report, to be published.

18. Hanley, R. D., 1975 “Effect of transducer flushness on fluctuating surface pressure measurements,” AIAA paper 75-534.

19. Michalke, A., \& Fuchs, H. V., 1975 “On turbulence and noise of an axisymmetric shear flow,” JFM 70 (1), pp. 179-205.

20. Panda, J., 2006 “Two point Space-Time correlation of density fluctuations measured in high velocity free jets,” AIAA paper 2006-0006. 